\title{
Family practice: meanings for modern times
}

\author{
Amanda Howe
}

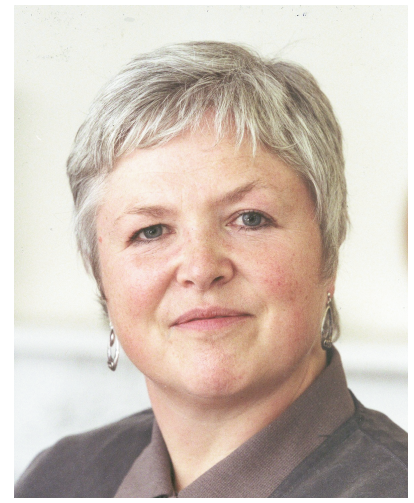

\section{INTRODUCTION}

The words 'family doctor' and 'family practice' are common in the language of GPs,' and 'family medicine' denotes a claim to medical speciality status in many countries where it remains possible to practise without a postgraduate qualification. ${ }^{2}$ Yet the image of family practice as manifest by William Pickles, the foundation President of the RCGP, appears both impractical and paternalistic from a 21st century perspective. The critical question raised in this lecture is whether family practice still has a unique significance at this stage of the development of medicine as a profession, and if so, what characterises this speciality, and how its principles can be passed on to future family practitioners. It concludes that the principles of family practice lie in the psychological aspects of doctor-patient interactions, and that the principles of sustaining therapeutic relationships need to be core to rigorous training and practice.

A Howe, MA, MD, MEd, FRCGP, professor of primary care, School of Medicine, Health Policy and Practice, University of East Anglia, Norwich. This text is based on the William Pickles Lecture delivered at the Royal College of General Practitioners Spring General Meeting, London, on 15 May 2009.

Address for correspondence

Professor A Howe, School of Medicine, Health Policy and Practice, University of East Anglia, Norwich NR4 7TJ.

E-mail: amanda.howe@uea.ac.uk

Submitted: 28 May 2009; Editor's response: 23 July 2009; final acceptance: 7 August 2009.

OBritish Journal of General Practice 2010; 60: 207-212.

DOI: 10.3399/bjgp10X483571

\section{THE SUBJECT OF THE PICKLES LECTURE}

The archives* of William Pickles' personal and professional papers reveal him as a 'family man': his marriage was long and happy, and he knew each of his patients intimately. He was, in Aysgarth, a 'father figure', who was consistently committed to the community he served for many years, and who went the extra mile to help them; something that we would normally associate with kith and kin. He himself was one of a large family: the son of a GP, one of six boys, five of whom were GPs, and the sixth wished to be. It can be assumed from this that there must have been a strong family identity around that shared career. His mother was a positive influence on his attitudes, he writes that she:

'... strove off an insufficient income to feed and clothe us and was in many ways a remarkable woman. I remember her as an advocate for old age pensions to stave off the inevitable workhouse long before it was put into operation ... and I remember her loving sympathy with the unmarried mother in an age when condemnation was the inevitable rule.'

Gertie and Patience were his wife and child, and formed part of his identity to patients who knew them as a family. The public record shows no major flaws in their happiness and commitment. The family ethos was one of service to the community, and both Gertie and Patience were a crucial part of his workforce. They helped him to sustain both his clinical and his research workload, doing his charts and assisting him to care for patients in other ways; for example, giving poor patients their shoes, and visiting the sick en route to parties.

But, for Pickles the epidemiologist, family was also a source of pathology: a route by which infection could be spread. Many of Pickles' studies show how infectious diseases were spread by interaction between family units, in which close contact of members was very likely to transfer and escalate epidemics. ${ }^{3}$ Embedded in this concept are the risks inherent in shared living, the issues of responsible

${ }^{\star}$ Quotes and anecdotes are from the Pickles archives at the Royal College of General Practitioners and Northallerton Public Records Office. 
versus irresponsible behaviours, and some questions around how difficult it is to resist the culture of family, which dictates the spread of both good and bad traits between its members. We know that, from a psychosocial perspective as well as a biological one, families can work for ill as well as good, and can be a source of grief as well as joy.

Will Pickles extended his activities to research, and to teaching medical students, which he loved and thought a great advantage:

'It is always a pleasure to entertain these and try to interest them in the advantages of general practice ... They think they learn something from me but I know I learn much from them. So many young doctors are aspirants for specialism, but those I see are hoping to enter GP [general practice] and I try to show them what a happy and useful life this can be.'

He contributed hugely to the improvement of the status of the discipline, including his role in the foundation of the Royal College of General Practitioners (RCGP). All this would have placed demands as well as opportunities on his family: the students often stayed at the family home, and although Gertie often accompanied him on his lecturing trips, this was not always easy or indeed possible. So another aspect of family practice that we recognise through Pickles is the almost inevitable colonisation of private by professional life. The evidence on younger doctors' balance of family and career commitments suggests that they have changed their expectations in the last 50 years, and the conditions under which Pickles exercised genuine personal engagement in clinical work, teaching, and research might be seen as overriding important professional boundaries. ${ }^{4}$

The world of Will Pickles and his family was very different from our world. There is a touching story in the archive of Pickles taking his daughter to a ball, but calling in at the house of a dying patient, who asks to see Patience in her finery:

'... the scene with the poor bloated invalid on her bed, the district nurse incredibly clean and neat, the queer old man, and the young girl a little selfconscious in her evening dress standing in the midst. ${ }^{5}$

Patience says that:

'There were many occasions when my father used me in this way when I was with him on his rounds'.

Sometimes the interests of a dominant individual make other parts of the unit subservient, or dependent.
It seems unlikely in the 21st century that Gertie would have been content to be his full-time research assistant, or Patience been willing to accompany her father to see patients; more likely she would have been driving herself to the ball, or jumping into a taxi with a group of girlfriends to party in Leeds. The image of an ever-present, infallible, brilliant renaissance 'man' who commands unquestioning respect is neither feasible or, perhaps, even acceptable in the 21st century. In fact Pickles, in the nicest possible way, could be seen as the epitome of 'paternalism' - an attitude that many people now reject. So if we retain the concept of a 'family' doctor, what are the dimensions of this that fit the 21 st century? What is the meaning of 'family' in 'family medicine', which many countries use to denote the speciality of general practice?

\section{NEW MEANINGS OF FAMILY PRACTICE}

Anthropological definitions have a broad scope: the 'family' is seen as a domestic unit, usually linked by blood or other clan relationships, where one or more members are dependent on the others for their mutual material and emotional function and sustenance. This definition shows us why cohabiting but independent student households are not family, where the childless but emotionally committed gay couple are; and go some way to explaining the legitimate claims for financial and emotional support of the extended family on a Chinese elder son and his English wife working in America, even though he has not lived in China for more than 10 years. There is a concept in family therapy of the 'psychological family': 6 a family that exists in a person's mind, but is not the same as his/her biological family. In a post-modern society, there are many variations on this theme that can fulfil nurturing and supportive functions, but in general, we do not know who a patient will count as 'family', or what this means to them.

So if you are a 'family' doctor, what family are you talking about? Few health systems insist on enrolling whole households onto one primary care service provider, and even if the whole household is on the same list they may see different staff members. The areas where the metaphor of family remains central to our practice, and also our teaching and professional direction, are, firstly, our knowledge and understanding of the impact of their families on the worldviews of our patients. There is the influence of those who are part of their current 'close others' on how they approach health care: their familial and cultural beliefs; and their own experiences of parenting, which will have strongly influenced how they think about, react to, and cope with health and illness. Family is a fundamental aspect of the way in which we identify ourselves and understand the meaning of who we are and what we have become. Families can be left, can be altered, and 
can become secondary to one's own preferred direction, but they are rarely forgotten.

A second pillar of family practice is that we work with the concept that knowing about a patient's family helps us to understand the developmental opportunities of both the consultation and the learning encounter. The College of Family Physicians of Canada draws our attention to this aspect of our work in part of their description of the family physician:

'Family physicians use their understanding of human development and family and other social systems to develop a comprehensive approach to the management of disease and illness in patients and their families. ${ }^{7}$

\section{THE PSYCHOLOGICAL BASIS OF FAMILY PRACTICE}

So what is core to that understanding? Most of our knowledge of how parenting experiences have an impact on us comes from the psychological literature, and some of our best disciplinary research (although not the research of Pickles himself) has focused on the interpersonal dynamics of the doctor-patient relationship as the 'mirror' of family experiences (Box 1). We see the fundamental need to be cared for, the inevitability of negative experiences, and the complex push-pull between nurture and developing independence. And the core concept of 'resilience':

'The ability to succeed, to live, and to develop in a positive way ... despite the stress or adversity that would normally involve the real possibility of a negative outcome'. ${ }^{8}$

We do not know if Pickles drew on psychodynamic work now regarded as fundamental in general practice, ${ }^{9}$ but he appears to have been highly dependable and protective to patients in their troubles. When we are vulnerable, we, just as children do, need essential emotional support - the 'professionalised holding function'10 - which good therapists provide, and which underpins the ability of patients to feel they have continuity with a doctor even if they are not always available. But there is a tension between dependency and autonomy, with both patients and students or other learners, and being aware of this tension enables us to evaluate the best ways to assist them. Our aim should be to make them as effective (or empowered) as they can be within the limits of their situation, at the same time accepting that by the nature of being an 'expert' we are there to offer them a service that they need, and that makes them dependent on us in some ways until the interaction and its outcomes are over. This again is the professional version of nurturing parents; holding people while growth, deciding, and healing occur, but ensuring that they, wherever possible, become independent over time.

Pickles' level of commitment to, and constancy within a community, is rare these days. We know that patients do want personal care from their doctors: that this increases patient satisfaction, it increases the job satisfaction of physicians, ${ }^{11}$ and it also increases the doctor's motivation to take responsibility for their patients and the consequences of their care.12 But while there are many examples of GPs who retain personal continuity, both patients and professionals frequently swap mutual dependency and obligation for a more boundaried, more autonomous, and also more complex service. Most patients will trade a timely appointment with a nurse for a routine screening with the need to wait or take a day off to see a GP: and most GPs do more than one thing, whether they have days out to teach, parent, politic, or run marathons. There is evidence from the archives that Pickles himself was increasingly absent from his practice: he records one patient as saying 'We've got two good doctors at Aysgarth, Dr and Mrs Coltman, and old Pickles isn't bad but he's always lecturing'!

So, the personal link between patient and doctor is likely to be more tenuous than it was in Pickles' day, but continuity is an important principle of 'family' practice: ${ }^{13}$ how do we reconcile these tensions? As Freeman's work shows,${ }^{14}$ continuity of care can be held by a team, a well-used set of records, an expectation, and an emotional bond. Perhaps the necessary aspect of continuity is that good doctors, and also nurses, will be there for us when we need them. Trust is associated more closely with effective interpersonal consultations than seeing the usual GP. ${ }^{15}$ Health staff who can engage with patients, who offer emotionally literate and effective consistent care, give us the sense of 'being there for us when we need them', albeit with some negotiations and limits to that availability. This is similar to the way in which a 'good enough' internalised parent figure acts; excellent family practice can make this available across a team and an organisation, even if unique personal continuity is impossible.

So, to summarise, a family can be a marvellous thing, but also a source of risk and even damage: a job as a family doctor can be a marvellous thing, but can

\section{Box 1. Psychological principles of effective doctor-patient} relationships.

- Core human need for respect and empathy 'unconditional positive regard'

- Accepting fear and anxiety

- Understanding dependency needs

- Act to support resilience and self-efficacy in the patient

- The aim of autonomy and improved self-reliance/autonomy 
also be costly to both the individual practitioner and their nearest and dearest. There are many opportunities in the consultation, not only for acute care and chronic disease management, but also real empowerment and support of personal growth. The skills of emotionally literate and consistent care are the core of high-quality care. But developing and using these skills is challenging, and is affected not only by our own values and opportunities, but also the preferences and expectations of others. The next section examines how modern practitioners learn to give personal care by using their professional self to help patients - and what support may be needed for them to achieve this.

\section{FAMILY PRACTICE AND PERSONAL CHANGE}

The evidence on the extraordinary influence of early childhood on the powers and problems of adults often leads to anxiety about determinism. Religious beliefs, psychological approaches, and even public health, all encourage us to hope that people can make better choices and reduce their own suffering in the process: a good GP never wants to believe that damage done in previous years cannot be overcome. Clinical experiences support this: people are extraordinarily courageous and resilient, their lives have been appalling but they may come out as good, strong, loving people anyway (see, for example, reference 16). At the same time, our professional experience teaches us to be sceptical, and to set our ambitions low: people are fallible, addicts relapse, the vulnerable lose their coping skills in the next crisis, and so on. The concept of individual 'habitus' is a useful one to show both the hard wiring of the past and the possibility of the present:

'[A] complex amalgam of their past and present ... that is always in the process of completion ... premised on familial legacy and early childhood socialisation ... a primarily dynamic concept, a rich interlacing of past and present, individual and collective, interiorised and permeating both body and psyche. ${ }^{, 17}$

\footnotetext{
Box 2. 'Tough love': dichotomies in the consultation.

- Nurturing and challenging the patient

- Listening and telling

- Allowing neediness while strengthening coping

- Indulgence and delegating responsibility

- Feeling - thinking

- Bonding - separation
}

It has a developmental quality, as does resilience a sense of both genetic and family context with personal uniqueness - believing in the possibility of a good outcome which is constructed through relationships. The first need of a good family doctor is therefore to believe that how we relate to patients can contribute to their positive development; being part of the environment where resilience can be further developed.

Pickles was an epidemiologist of infections, following their patterns over the community and time. Family doctors also need to be epidemiologists of life events and narratives, following the patient's understandings of crucial events and others in their lives. ${ }^{18}$ Mental health workers adopt a 'history taking plus' approach found to be beneficial in patients with recurrent emotional and psychological problems: ${ }^{19}$ taking a family history, not in the genetic but in the developmental sense; getting some flavour of how the patient remembers and reacts to these memories; and making a 'formulation', an assessment of their likely strengths and vulnerabilities as part of our overview of the patient. Not only do we need to have knowledge of this, but we need to use it effectively in helping our patients to understand and manage their problems. If you believe in person-centred practice, then you must work with the person, and to do that you must know something of why they are who they are. The retelling of one's story in itself can assist the development of resilience, by creating over time a cohesive narrative, and working through the consequences of emotional damage. ${ }^{20}$ Doctors who are able to foster insight, strengthen coping mechanisms, develop emotional resilience, and enable patients to maximise their health are those who are willing and able to enter into a genuine interpersonal relationship, often for only 10 minutes, but being genuinely 'there' for the patient. But this is 'tough love'; balancing both ends of the spectrum by using the relationship and insights you have into this person (Box 2).

And what's the cost? Not much, if you are used to it: slightly longer consultations, but better outcomes in terms of satisfaction, psychological wellbeing, and clinical effectiveness. ${ }^{21}$ For many GPs this becomes an unconscious expertise; they walk in every day and do it with most patients, and they are respected, indeed loved, for this. Such GPs may in part be 'born like that', but more are made. Pickles was a good doctor and educator because he had been raised by a loving and resilient family who prized general practice and made themselves in its image, and he chose to make himself available to his patients and students, both physically and emotionally. But to do this, GPs have to be able to use their professional self, their 'persona' to the most effective ends..$^{22}$ This is not an automatic consequence of living in a more open emotional culture than in 
Pickles' time: we should be conscious of how we can train others to do this, more conscious than previously, given the needs of our patients for an ever more person-centred approach - to develop ourselves as generalists whose knowledge and consulting skills draw on these principles, who use them routinely without burning out.

\section{LEARNING TO BE FAMILY ORIENTED}

GPs bring the human into their teaching as well as their clinical practice. But teaching individuals well on an occasional basis is not enough: we need to develop a culture across all learning settings of working with the person to develop them as a professional. Historically, medics have not considered this part of their role; indeed, I think Pickles might have found it rather odd to find himself expected to reflect on his relationships with learners and patients, but there is some evidence on how training can result in people who are effective with people, through their interpersonal relationships, for improved wellbeing.

Some principles used in modern medical training ${ }^{23}$ can be summarised as:

- Select people who already show some interpersonal strengths that can be built on in training: autonomy, resilience, team orientation, and self-questioning.

- 'Hold' them while giving them challenges. Make sure they are known, have some tutor/mentor continuity over time, and that they get feedback on how they perform as they develop; those 'learning conversations'.

- Make them reflect on themselves and how they work: in teams, with patients, what their strengths and weaknesses are. ${ }^{24}$

- Make them think: about professional challenges, difficult relationships, where things go wrong, what they could do differently. Eraut's bringing of the tacit unconscious into conscious competent control. ${ }^{25}$

- Make them safe - as much as possible - so they can experiment with this before being exposed to major challenges, and while experiencing these. ${ }^{26}$

- Have regular supervision on clinical cases where they can discuss complex needs generated by doctor-patient relationships, transference and counter-transference, the emotional burden of caring; because of the need for the professional sometimes to be 'held' in order to hold others. ${ }^{27}$

- Encourage a virtue ethic, work with why and how they want to help, rather than when they think they should, and be open to exploring areas they dislike.

- Encourage boundaries and stress release, avoiding burnout, and setting limits.

- Challenge defences and emotional resistance early on; it can only get worse.

- Work with them as you would a patient, following their preference and abilities, but keeping your eye on their needs and those of society, aiming for better outcomes. ${ }^{28}$

- Most of all, treat them with respect and treat them as equals.

These kind of approaches need to become endemic in all clinical and training settings: one good GP, or one good trainer, is not enough, especially when learning, just like most clinical care, has to be spread over more than one setting or organisation. Not everyone has friends or family who can do even the basic support and emotional challenge for them, as we have said, the days of Will's reliance on Gertie are past, and in any case we know that to impose our professional needs on our loved ones is often inappropriate and sometimes unhelpful. So we must look to our peers in practice to assist us in maintaining an effective family ethos in our practice and learning.

This brings us to the meaning of family practice in the wider context: the practice team as a family, the interpersonal dynamics of organisations, being resilient to political change, and managing both negative and positive emotions when marketing our skills. Martin Marshall's Mackenzie lecture discussed the changes required of family practice by contemporary circumstances; ${ }^{29}$ this contrasts with the intimate world of the consultation, the learning relationship, and the function of family and its reflection into our practice. But insight into the family 'system' is often also useful when analysing organisational dynamics and leadership styles. Some of the resistance we meet, the mocking of the unmeasurable, ${ }^{30}$ or the fragmentation of personal care in favour of service access, ${ }^{31}$ may be because none of us like to remember when we are weak, vulnerable, or failing. Pickles reminds us that 'All those who come to you are very frightened individuals and must receive the respect and consideration which one man [sic] owes another', and this needs careful handling in the workplace as well as the consulting room. There are 'family' issues in the changing workforce: staff may be more willing to engage with patients emotionally when they are working less than full time, so altered work patterns may facilitate some aspects of fuller emotional engagement with patients, without excessive risk of dependency. We need to be particularly alert to the different professional challenges for women doctors, because our society still encourages women more than men to be 'carers' and do 'caring', both domestically and professionally. Also, because patients similarly tend to consult with women when they are vulnerable, there are different risks to them as practitioners around setting boundaries and avoiding burnout. ${ }^{32}$ We must also work in the outer world for prevention of psychological damage which leaves its marks on so many generations - advocating 
for peace, for economic stability, for healthy psychological living conditions, for avoidance of severe personal damage - as Cyrulnik says, 'the triumph of the wounded never exonerates the aggressors'. ${ }^{8}$

How does this apply in the RCGP? Any family system has strong traditions and habits, there are organisational dynamics that are driven by personalities, there are projections and denials. Things go wrong in families, tempers fray, relationships change, and so on. But a healthy family is one that is resilient, that 'does not rely on evasion of risk, but works through successful application of protective factors to engage in adverse situations and emerge from them stronger' ${ }^{33}$ Increasing the strength of those factors that improve resilience will help a family or an organisation perform better. Common values, commitment, taking responsibility for what needs to be done, and a certain amount of flexibility makes families and organisations work well: a balance of autonomy and collaboration, emotional give and take. And this can work for the global community of family practitioners as well. We have fantastic scope now, through the e-environment to be in touch with colleagues all over the world, and to be part of their family. They can become part of our professional and psychological world - a virtual family - and this again can be used for learning, for support, and for widening our views of the possibilities of practice. It is also crucial to achieving global family health goals, and to reducing the profound inequities of the current world health situation. ${ }^{34}$

\section{CONCLUSION}

The ultimate meaning of family practice in modern times is to learn to be 'there for each other': and to create working environments where we can be genuinely, fully there for patients, for colleagues, for staff, for the profession, and for our own family and friends. Our efforts, our training, our working conditions, and our professional development should assist this ability to 'be here' as much as possible. At its best, the RCGP is like that too: somewhere, when all is said and done, that we can 'be' - be valued, be developed - and that we should be able to look to for nurture and companionship.

\section{Discuss this article}

Contribute and read comments about this article on the Discussion Forum: http://www.rcgp.org.uk/bjgp-discuss

\section{REFERENCES}

1. Allen J, Gay B, Crebolder H, et al. The European definitions of the key features of the discipline of general practice: the role of the GP and core competencies. Br J Gen Pract 2002; 52: 526-527.

2. Bailey T. Is family medicine a specialty? YES. Can Fam Physician 2007; 53(2): 221-223.

3. Pickles W. Epidemiology of country practice. 3rd edn. London: Royal College of General Practitioners, 1984.

4. Feldman MD, Christensen JF. Behavioural medicine in primary care.
Maidenhead: McGraw Hill Professional, 2003

5. Pemberton J. Will Pickles of Wensleydale: the life of a country doctor. 2nd edn. London: Royal College of General Practitioners, 1984.

6. Boss P. Loss, Trauma, and resilience. Therapeutic work with ambiguous loss. New York, NY: Norton and Co, 2006.

7. The College of Family Physicians of Canada. Four principles of family medicine.

http://www.cfpc.ca/English/cfpc/about\%20us/principles/default.asp?s= 1 (accessed 26 Jan 2010).

8. Cyrulnik B. Resilience. London: Penguin, 2009.

9. Balint M. The doctor, his patient and the illness. London: Pitman, 1957.

10. Urdang E. Human behaviour in the social environment: interweaving the inner and outer worlds. New York, NY: Haworth, 2002.

11. Blankfield RP, Kelly RB, Alemagno SA, King CM. Continuity of care in a family practice residency program. Impact on physician satisfaction. $J$ Fam Pract 1990; 31(1): 69-73.

12. Hjortdahl P. Continuity of care: general practitioners' knowledge about, and sense of responsibility toward their patients. Fam Pract 1992; 9(1): 3-8.

13. Guthrie B, Saultz J, Freeman GK, Haggerty J. Continuity of care matters. BMJ 2008; 337: a867.

14. Freeman GK, Shepperd S, Robinson I, et al. Continuity of care: report of a scoping exercise for the SDO R\&D programme of the NHS. London: National Coordinating Centre for NHS Service Delivery and Organisation Research and Development, 2001.

15. Tarrant C, Colman A, Stokes T. Past experience, 'shadow of the future', and patient trust: a cross-sectional survey. Br J Gen Pract 2008; 58(556): 780-783.

16. Sally Sara. Gogo Mama: a journey into the lives of twelve African women. Sydney: Pan MacMillan, 2007.

17. Reay D. 'Always knowing' and 'never being sure': familial and institutional habituses and higher education choice. J Educ Policy 1998; 13(4): 519-529.

18. Greenhalgh T, Horwitz B (eds). Narrative based medicine: dialogue and discourse in clinical practice. London: BMJ Books, 1998.

19. Mace C, Binyon S. Teaching psychodynamic formulation to psychiatric trainees. Part 1: basics of formulation. Advances in Psychiatric Treatment 2005; 11: 416-423.

20. Dowrick C. Beyond depression. Oxford: Oxford University Press, 2004.

21. Phillips S, Austin E. The feminization of medicine and population health. JAMA 2009; 301(8): 8 .

22. Harre R. The singular self: an introduction to the psychology of personhood. London: Sage, 1998.

23. Howe A, Campion P, Searle J, Smith H. New perspectives approaches to medical education at four new UK medical schools. BMJ 2004; 329(7461): 327-332.

24. Launer J. Moving on from Balint: embracing clinical supervision. Br J Gen Pract 2007; 57: 182-183.

25. Howe A. Professional development in undergraduate medical curricula — the key to the door of a new culture? Med Educ 2002; 36(4): 353-359.

26. Prins JT, Gazendam-Donofrio SM, Dillingh GS, et al. The relationship between reciprocity and burnout in Dutch medical residents. Med Educ 2008; 42(7): 721-728.

27. Kilminster S, Jolly B. Effective supervision in clinical practice settings: a literature review. Med Educ 2000; 34(10): 827-840.

28. Rogers C. On becoming a person. London: Constable, 1961.

29. Marshall M. Practice, politics and possibilities. Br J Gen Pract 2009; DOI: 10.3399/bjgp09X420266.

30. Benson $\mathrm{T}$, Whatling J. The only way to find out if your healthcare strategies are working is through reliable measurement. Health Serv J 2008; 13 Aug: http://www.hsj.co.uk/tim-benson-and-justin-whatlingon-measuring-outcomes/1767225. article?query $=0 \& \mathrm{v}=1$ (accessed 12 Feb 2010).

31. Department of Health. High quality care for all. NHS next stage review. Final report. London: TSO, 2008.

32. McMurray JE, Linzer M, Konrad TR, et al. The work lives of women physicians: Results from the physician work life study. J Gen Intern Med 2000; 15(6): 372-380.

33. Benzies K, Michasiuk R. Fostering family resiliency: a review of the key protective factors. Child and Family Social Work 2009; 14: 103-114.

34. World Health Organization. The world health report: primary care now more than ever. Geneva: WHO, 2008. 